\title{
NATURAL HISTORY OF A SUBSOCIAL \\ TORTOISE BEETLE, ACROMIS SPARSA BOHEMAN (CHRYSOMELIDAE, CASSIDINAE) IN PANAMA
}

\author{
By Donald M. Windsor \\ Smithsonian Tropical Research Institute, Apartado 2072, \\ Balboa, Republica de Panama
}

\section{INTRODUCTION}

Insects are said to be "subsocial" if either or both parents directly involve themselves in the care of their own offspring after hatching (Michener 1969, Eickwort 1981). The literature suggests that parental care occurs in a few neotropical chrysomelid beetles. Surprisingly, there have been few reports on the natural history of these species. Below I describe aspects of the behavior, ecology, and morphology of Acromis sparsa Boheman, a "tortoise-beetle" common throughout the Republic of Panama.

The life histories of subsocial insects are known to differ greatly. In some species parents provision offspring with food, while in others parents buffer offspring against extremes of the physical environment or shield offspring from predators and parasites (Wilson 1971, pp 121-135; Eberhard 1975). Females are the providing sex in most subsocial insects.

Parental care has been reported in only nine of several hundred families of coleopterous insects (Hinton 1944). The trophic habits of these groups are diverse, embracing the eating of flesh (Tenebrionidae, Hydrophilidae), carrion (Silphidae), dung (Staphylinidae, Scarabeidae), decomposing wood (Passalidae), fungi (Scolytidae and Platypodidae) and green leaves (Chrysomelidae). Of the three chrysomelid species listed by Hinton (1944) as displaying subsocial habits, all are members of the subfamily, Cassidinae.

The Cassidinae ("tortoise beetles" or "gold bugs") is a large subfamily comprised of more than 3,000 species distributed world-wide and reaching greatest diversity in tropical latitudes (Arnett 1968, p. 941). Larvae of many species are slow-moving, leaf-feeders whose

1) Corresponding address: STRI, APO, MIAMI 34002-0011.

Manuscript received by the editor February 26, 1987. 
concealment and defense is enhanced by the accumulation of fecal matter and exuviae on a caudal fork held over the body and used against predators (Shelford 1916, p 175; Eisner et al. 1967). The adults of many Cassidinae are conspicuous, diurnally-active insects especially abundant on young or rapidly growing vegetation.

References to subsocial habits in the Cassidinae are few and all come from the Neotropics. Ohaus (1899-1900) observed adult female Omaspides (Omoplata) pallidipennis Boheman clinging to the backs of larvae on the undersurfaces of Passiflora leaves in Peru (Abb. 205 in von Lengerken, 1954; also Fig. 118, p 62, O'Toole and Preston-Mafham 1985). Ohaus (1909) noted that another cassidine, Pseudomesomphalia (Neomphalia) thallassina Boheman, shielded tightly aggregated larvae with its elytra. Fiebrig (1910, Abb. 1a) observed female Acromis spinifex (= Selenis spinifex L.) guarding stalked egg masses in Paraguay (redrawings of this figure, Fig. 156/1 in Linsenmaier 1972, p 156 and Abb 206 in von Lengerken 1954 , erroneously have a male guarding the egg mass). Fiebrig's observations did not indicate how long mothers guarded their offspring or from whom they were being guarded.

The genus Acromis Chevrolat (Selenis Hope) (Tribe: Stolaini, Hincks 1952) is comprised of four species whose ranges appear to meet or overlap in Amazonia. A. sparsa has been collected from Mexico south through Central America into Brazil and Bolivia (Blackwelder 1982, p 743). Extensive collecting by H. Stockwell and others in Panama has turned up only $A$. sparsa. A. nebulosa Boheman has been collected in Brazil, Peru and Bolivia; $A$. spinifex L. in Guadeloupe and other locales in South America (Paraguay) and $A$. venosa Erichson (illus. no. 186/16, Linsenmaier 1972, p 186) in Peru and Bolivia. I have found no reports on parental care in either $A$. venosa or $A$. nebulosa; however, the similarities in adult morphology throughout the genus suggest similar habits.

\section{Methods}

Observations and specimens were collected at low to middle elevations $(0-500 \mathrm{~m})$ in central Panama where $A$. sparsa is abundant in disturbed areas and is rarely, if ever, observed under closed forest canopy or in forest light-gaps. $A$. sparsa is not seen, for example, on Barro Colorado Island, nor has it been recovered from the light traps run there by $\mathrm{H}$. Wolda for 13 years. However, $A$. sparsa is an 
abundant insect in second growth on the mainland at Frijoles, 4-5 $\mathrm{km}$ away and is found in disturbed habitats across the Isthmus of Panama including areas of quite different mean annual rainfall (1.8 $\mathrm{m}$ on the Pacific side versus $3.2 \mathrm{~m}$ on the Caribbean side). This beetle has become common along the El Llano-Carti Road (approximately $45 \mathrm{~km}$ east of Panama City), an area converted from forest to second-growth within the past 15 years.

Quantitative observations of $A$. sparsa were made in mid-isthmus at three sites within $15 \mathrm{~km}$ of one another, primarily between August and November of 1978. The "mixed" site is a roadside transect through grass and young forest along the Pipeline Road, 3-6 kms NW of Gamboa ( $\left.79^{\circ} 42^{\prime} \mathrm{W}, 9^{\circ} 07^{\prime} \mathrm{N}\right)$. The "field" site is an expanse of tall grass, occasional shrubs and vines at the beginning of the Pipeline Road, $2 \mathrm{~km} \mathrm{NW}$ of Gamboa. The "forest" site is shaded $1 \mathrm{~km}$ transect along the Old Gamboa Road, $7 \mathrm{~km}$ SE of Gamboa.

\section{FOOD-PLANT}

The life history of $A$. sparsa is closely tied to a single host-plant, Merremia umbellata L. (Convolvulaceae). The range of $M$. umbellata includes S. Florida, W. Indies, Mexico, Central and South America and much of the Old World Tropics (Austin 1975). I have never observed $A$. sparsa feeding on other plant species although I have occasionally found larvae and pupae "stranded" on vegetation touching their food plant. Merremia umbellata is a common roadside vine which grows rapidly in the early wet season using support from grasses, dead shrubs, etc. to reach sunlight. Older plants have a substantial underground tuber which sends out a network of aboveground runners, each of which gives rise to numerous vertically climbing shoots. During the first four to six weeks of the wet season $M$. umbellata grows rapidly and may form a closed canopy over second-growth vegetation. Growth slows during the late wet and dry season and fewer leaves are supported. Flowering occurs in January of most years.

Merremia umbellata has many casual and host specific herbivores including at least six species of Cassidinae. This is the richest assemblage of Cassidinae on a single plant species that $I$ have observed in Panama. Of these species, only $A$. sparsa is subsocial, three are solitary in all stages and two have eggs in clutches-one of 
these has gregarious larvae. A. sparsa is probably the most important herbivore on $M$. umbellata because of its abundance throughout the wet season and its exploitation of apical foliage.

\section{SEASONALITY}

Acromis sparsa populations were not systematically censused so I can only present a subjective account of activity through the year. Reproduction ceases during the dry season, January through April of most years. The few adults observed during this period were usually associated with host plants rooted in permanently moist habitats. The onset of the rains in early or mid May brings increased growth by the host plant and the reappearance of $A$. sparsa males and females on new growth. Females immediately begin to oviposit. A second round of mating and oviposition begins in late June and early July. Several more synchronized reproductive bouts follow at approximately two month intervals before dry season conditions set in. Although abundance appeared greatest in the mid wet season there were few times when adults could not be found in quantity just by inspecting the host plant. There were exceptions such as when females were guarding pupae or periods following the emergence and first feeding of tenerals. Adults and the larval groups they were attending also suddenly became rare during extended rainless periods within the wet seasons of some years.

\section{The Egg Stage.}

Location and composition of the egg mass

Eggs were deposited in masses (Fig. 1a) attached to the undersurfaces of leaves. Each egg is anchored to the midrib by a flexible, lacquer-like thread which fuses with other threads producing a short (3-5 $\mathrm{mm})$ pedicel holding the egg mass out toward the leaf apex. Eggs are smooth and ovate $(0.5 \times 1.5 \mathrm{~mm})$, and are stuck firmly to one another during oviposition in two to three orderly layers forming the final $10-15 \mathrm{~mm}$ of the egg mass. The stiffened egg mass provides a roosting platform for the guarding mother during egg development.

Although oviposition is often under the first or second unfolded leaf, egg masses are often encountered under the third, fourth or fifth leaf since several new leaves normally unfold during the 12 days it takes eggs to develop (Table 1). The distal portion of many leaves 

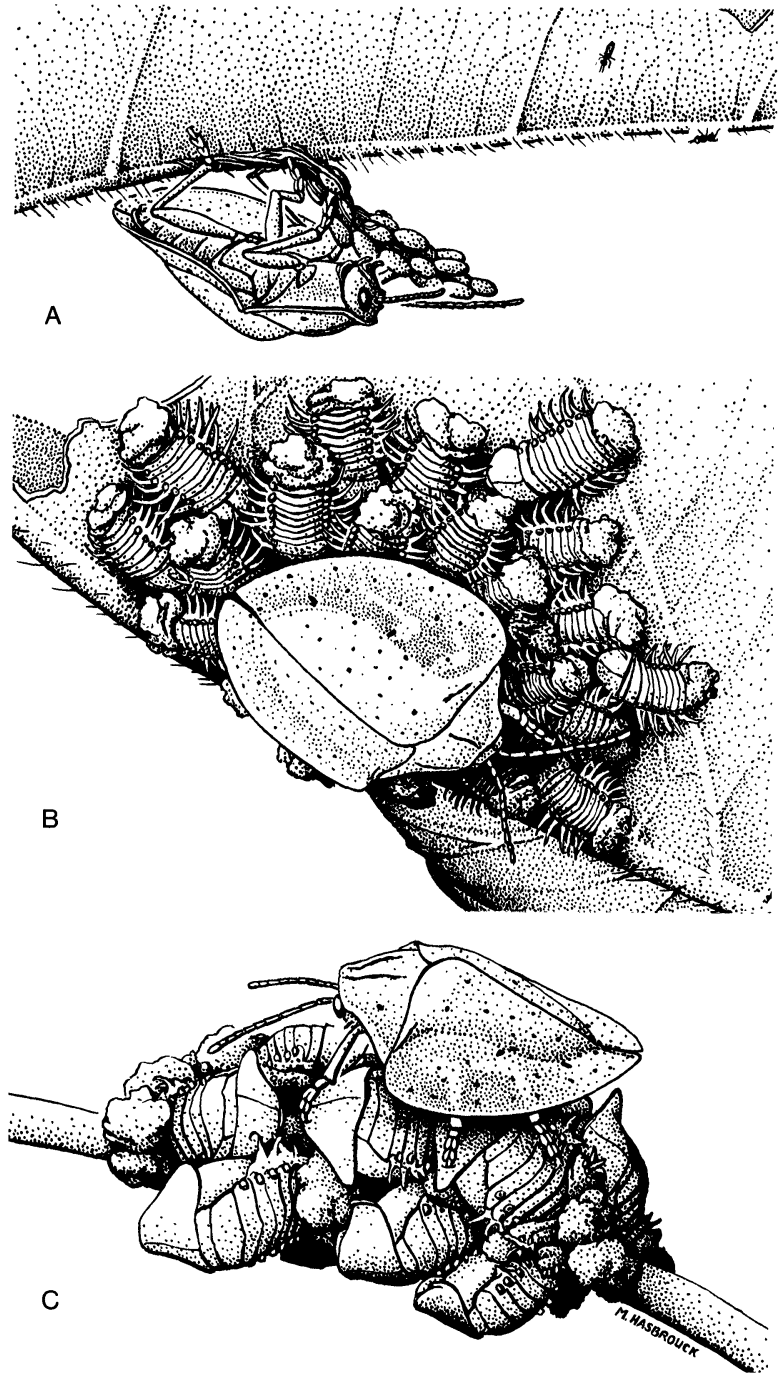

Fig. 1. Guarding postures of female Acromis sparsa. A, on an egg mass with parasites nearby; $B$, on medium-aged larvae aggregated on the undersurface of a Merremia leaf; and C, on a pupal mass located low on a Merremia stem. 
with egg masses tended to droop slightly. Leaf hairs and the mid rib near the egg mass on these leaves were chewed by the female prior to oviposition. The significance of this behavior is unclear. A drooping leaf increases concealment of the female on her clutch. It also better shields them from insolation. Bruising of the leaf tissue may mechanically prepare the site for the first feeding of her larvae or prevent the induction of plant defensive chemicals to the area of first larval feeding.

The median number of eggs per egg mass is $40(n=126$, range $=$ 13 to 49). The frequency distribution is skewed to the left (Fig. 2). The number of eggs per egg mass did not differ significantly between the three study sites (Kruskal Wallis one-way analysis of variance, $\mathrm{H}=1.99$, $\mathrm{df}=2, \mathrm{p}=0.37$ ). The number of eggs in an egg mass and the width of the guarding female's elytra were positively correlated (Spearman $r=0.75, n=46, p<0.01$ ). Although the number of eggs per egg mass is correlated with female size, other factors such as mother's age or ovipositional history may also influence clutch size.

Table 1. The distribution of (A) large, solitary males, (B) solitary females, (C) copulating pairs, (D) females on eggs, (E) females with larvae, and (F) the number of leaves on $M$. umbellata vines recorded by leaf number from the first unfolded leaf at the apex. Median values are indicated by asterisks.

\begin{tabular}{|c|c|c|c|c|c|c|}
\hline $\begin{array}{l}\text { Leaf } \\
\text { Number }\end{array}$ & A & B & C & D & $\mathrm{E}$ & $\mathbf{F}$ \\
\hline 1 & 9 & 1 & & 4 & & \\
\hline 2 & 9 & 12 & 1 & 3 & & \\
\hline 3 & 17 & 6 & 4 & 11 & & \\
\hline 4 & $* 15$ & 3 & $* 2$ & $* 11$ & 2 & \\
\hline 5 & 9 & * 2 & 1 & 10 & 2 & 2 \\
\hline 6 & 6 & 4 & 3 & 4 & 2 & 4 \\
\hline 7 & 1 & 4 & 1 & 5 & 4 & 1 \\
\hline 8 & 3 & 6 & & 3 & 1 & 3 \\
\hline 9 & 2 & & 1 & 2 & * 5 & 3 \\
\hline 10 & 1 & & & 3 & 2 & 1 \\
\hline 11 & 3 & 1 & & & 1 & 7 \\
\hline 12 & 2 & 1 & & & 1 & *2 \\
\hline 13 & 1 & & 1 & 1 & 1 & 2 \\
\hline 14 & 2 & 2 & & 1 & 1 & 2 \\
\hline 15 & & 1 & & & & 4 \\
\hline 16 & & 1 & & & 1 & 2 \\
\hline$>16$ & 3 & 1 & 14 & & 1 & 11 \\
\hline Totals & $\overline{83}$ & $\overline{45}$ & $\overline{14}$ & $\overline{58}$ & $\overline{24}$ & $\overline{44}$ \\
\hline
\end{tabular}


Females were able to rapidly replace a missing egg mass. Egg masses were removed from eighteen guarding females during the last week of May 1984. Nine of these females were discovered nearby on new egg masses the following week. The difference in the average number of eggs in original and replacement egg masses, 37.4 and 35.5 respectively, was not significant (Mann-Whitney $U$ test, $\mathrm{U}=38, \mathrm{p}>0.05$ ).

\section{Egg parasitoids and hatching success}

Mothers frequently moved in a jerky manner on or near their egg mass when parasitic Hymenoptera (unidentified Eulophidae) were present. Wasps normally landed on the undersurface of a leaf 2-4 $\mathrm{cm}$ away and oriented toward the eggmass (Fig. 1a). From this position they darted directly to the eggmass to oviposit. Movements by the wasps on the leaf appeared to stimulate $A$. sparsa females to rapidly move back and forth and around the eggmass for short periods of time. Wasps were also observed resting on the elytra of brooding females, females without offspring and occasionally on males. Carroll (1978) mentioned similar phoresy by a eulophid wasp on a Brazilian cassidine beetle, Stolas sp..

To assess the importance of egg parasitoids, a total of 103 abandoned egg masses were collected from three habitats between late August and early November 1978 and examined egg by egg for the small exit hole of an emerging wasp or the larger serrated opening of an $A$. sparsa larva. These eggs, numbering 3893, produced 1004 wasps $(26 \%)$ and 2342 larvae (60\%). Five hundred and forty-seven eggs (14\%) failed to develop. Significant differences existed between habitats in the number of wasps and the number of undeveloped eggs per egg mass (Table 2). The median number of wasps emerging from egg masses was greatest at the "field" site, least at the "forest" site and intermediate at the "mixed" site. The median number of undeveloped eggs was also much higher at the "field" site than either of the other two sites. Thus, $A$. sparsa females were most successful in producing larvae at the "forest" site, intermediately successful at the "mixed" site and least successful at the "field" site. It is unclear why some eggs fail to hatch. That undeveloped eggs are more common where egg parasitoids are more abundant suggests that multiple ovipositions by parasitoids might be responsible. Physical conditions, especially maximum daytime temperature and humidity, also differ between shaded and open sites. 


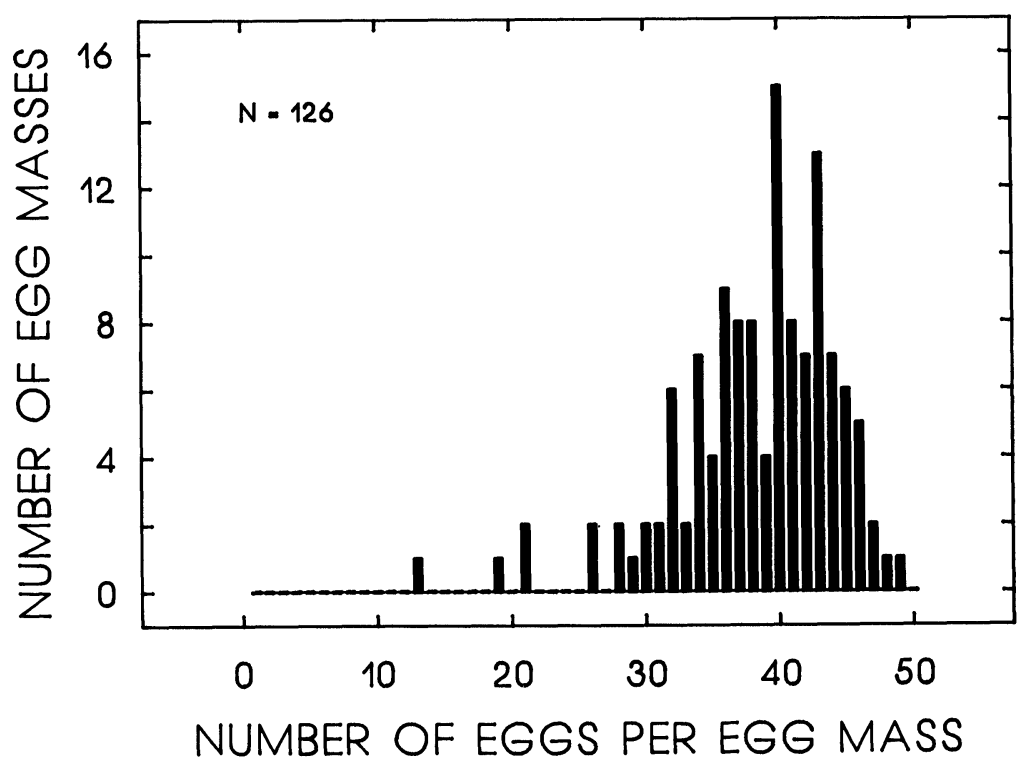

Fig. 2. Variation in the number of eggs per egg mass.

One or more wasps emerged from 79 of $103(77 \%) A$. sparsa egg masses (26\% of all eggs). None of the egg masses, however, was completely parasitized-85\% was the highest value obtained. In contrast, Carroll (1978) found 86 percent of egg clutches $(n=117$, 31.5 eggs per clutch) of Stolas sp., a Brazilian cassidine that does not have maternal guarding, were completely parasitized by wasps; 14 percent were totally unparasitized. Thus, guarding may make it less likely that all eggs in an egg mass are parasitized.

Eberhard (1975) noted that maternal guarding by the pentatomid, Antiteuchus tripterus Ruckes, was highly effective against generalist predators and phoretic egg parasitoids. However, when he removed mothers from their clutches, the number of eggs parasitized actually decreased because parasitoids apparently used olfactory or visual cues associated with the mother to locate egg masses. This may also occur with $A$. sparsa and deserves investigation.

Opportunistic predators of eggs

The importance of maternal guarding during the egg stage was investigated by locating eighteen egg masses with mothers at the 
Table 2. The median number of eggs per egg mass producing wasp parasitoids, beetle larvae or failing to develop classified by collection site. The Kruskal Wallis one-way analysis of variance statistic, " $\mathrm{H}$ ", tests for significant between-site differences (“*” = p 0.001).

\begin{tabular}{|c|c|c|c|c|}
\hline Site & Wasps (\%) & Larvae (\%) & Undevel. (\%) & Eggs $N$ \\
\hline Field & (35) & (32) & $11 \quad(28)$ & 40 \\
\hline Mixed & (26) & $25 \quad(64)$ & $2 \quad(5)$ & 39 \\
\hline Forest & (5) & $30 \quad(75)$ & (5) & 40 \\
\hline H & $11.7^{*}$ & $25.3^{*}$ & $21.2^{*}$ & $1.99 \mathrm{~ns}$ \\
\hline
\end{tabular}

"forest" site during the mid wet season 1984. The sample was divided into nine matched pairs consisting of an egg mass from which the mother was removed and the nearest neighboring egg mass from which the mother was removed and immediately replaced. Each egg mass was revisited 6 times at intervals of 24 hours. The unguarded egg mass was missing or destroyed before the guarded eggmass in each pair. Five of nine motherless egg masses were preyed upon within 24 hours, eight of nine within three days and all nine within five days. Myrmecine ants consumed two of the unguarded egg masses. Eight of nine "control" egg masses and mothers were intact and in perfect condition at the end of the five days. One "control" egg mass was sandwiched between two wet leaves during a rain and subsequently abandoned by the guarding female. This egg mass was also overrun by myrmecine ants.

Relocating and discriminating between egg masses

Females were removed from egg masses and dropped so that they landed within 1-2 m of a point on the ground directly beneath their egg mass. In most cases these females returned to their egg mass within 30-60 minutes. When females were moved more than 2 meters from the egg mass they rarely returned. Females that lost their own egg mass as a result of being displaced readily adopted and protected the first unguarded eggmass they came upon, even if it was not their own. However, when 12 marked mothers from six pairs of neighboring egg masses (located on different shoots of the same plant) were removed and dropped on the ground midway between their egg masses, 11 returned to their own egg mass. The exceptional mother adopted a nearby untended group of $A$. sparsa larvae, perhaps because her egg mass was being preyed upon by ants. Two females from one of the pairs were observed guarding the 
same egg mass for roughly 15 minutes. One of the females lost interest, walked away and later encountered her own eggs on another shoot of the same plant. Thus it appears that $A$. sparsa females can home from limited distances and can discriminate between their own egg mass and those of their neighbors, behavioral capabilities strikingly similar to those described by Tallamy and Denno (1981) for the subsocial tingid, Gargaphia solani Heidemann.

\section{LaRval Period}

\section{Grazing pattern}

Larvae begin to graze on the under surface of their natal leaf immediately after eclosing from the egg. Young larvae consume the lower epidermis and part of the mesophyll leaving the upper epidermis intact. Later instars consume the entire leaf, save the central midrib. First instar larvae advance slowly in an organized front on their natal leaf, grazing a path along one side toward the tip and then back toward the petiole along the other side of the leaf. Two to three days are spent on the first leaf where two molts are completed. Larvae then move down the pedicel to the stem where they have the option to move toward younger leaves at the tip or toward older leaves further down the plant. Nine of ten larval groups observed at this juncture moved toward the vine apex (2-sided, Binomial probability $=0.04)$. Later, after apical leaves are eaten, the family descends along the stem to feed on older leaves.

Acromis sparsa mothers normally stay behind their moving larvae and do not appear to influence their movements. When larvae stop feeding they form a tight knot of bodies encircling the stem or a flat rosette of bodies under a leaf (Fig. 1b). Mothers often stand on the backs of their larvae but move to the edge or off of the group to challenge any approaching arthropod. Larvae spend most of their time on the undersurfaces of leaves and at night remain tightly aggregated and defended by their mothers. In contrast, Ohaus (1909) noted that female Omaspides shielded their aggregated larvae during the day, possibly from the effects of the sun, and that larvae wandered apart at night to feed.

\section{Predation on larvae}

Guarding has the appearance of being highly effective at thwarting predators. However, there are at least two circumstances in 
which predators seem to have an advantage. When $A$. sparsa larvae move between feeding sites they normally move 2-6 cm ahead of their mother. In so doing they are unguarded and on several occasions I observed chalcid wasps (probably Spilochalcis sp.) flying in tight circles around and briefly landing on these moving groups of larvae. This may be especially common as groups composed of older larvae move the 1-2 m down the vine to a pupation site. Mothers did not shield or otherwise defend their offspring under those circumstances and may not have sensed the danger. Larvae also became vulnerable to predators if their aggregation became divided into two groups, only one of which could be competently guarded. Predacious bugs, especially Stiretrus spp. (Pentatomidae, Asopinae), were adept at creating and exploiting this situation. Females could charge and "bulldoze" a Stiretrus adult from an area with larvae. However, repeated approaches by the bug were eventually rewarded by the temporary isolation of some larvae, some remaining on the under surface of the leaf while the others had moved to the top, etc. These were quickly speared and sucked dry. Predacious bugs tended to remain with a family group for several days, often until offspring were gone. Orphaned larval groups were only rarely encountered. Individuals within these groups were usually tightly aggregated suggesting that the presence of the mother is not crucial to maintenance of the aggregation. Poorly aggregated, orphan groups were also occasionally found. Individuals in these groups were usually few in number implicating predators or parasitoids as the disruptive factor. Aggregated larvae did not disperse nor did mothers react when I presented injured or crushed members of their group indicating the absence of an effective volatile alarm substance.

Larval mortality in defended groups

Natural levels of larval mortality were examined at the "field" and "forest" sites during August and September 1978. Due to the differences in egg mortality described above only 8 of 19 females and brood reached the larval stage at the "field" site; all of 22 at the "forest" site. Additionally, the initial number of larvae per mother differed significantly between sites; 29 larvae per group at the forested habitat versus 14 in the old field site (Mann Whitney U Test, $\mathrm{z}=4.14, \mathrm{p}<0.001)$. The rate of larval disappearance, roughly 1.2 larvae per day (Fig. 3), did not differ between sites (Mann Whitney $\mathrm{U}$ Test, $\mathrm{z}=0.133, \mathrm{p}=0.45$ ). Larvae from only one of eight groups 
( 8 individuals, $3 \%$ ) reached pupation at the "field" site while larvae from 15 of 22 broods (96 individuals, 11\%) reached pupation at the "forest" site ( $p<0.01$, Fisher's Exact test).

Larval mortality in undefended groups

The effect of maternal guarding on larval survival was investigated during August 1980 by removing mothers from some larval groups and comparing their survival to that of nearby guarded groups at similar stages of development. Initially, six nearestneighbor pairs, groups with and without mothers, were found, marked and revisited daily. The unguarded group disappeared first in each of the six pairs. All unguarded larvae were gone within three days. One week later the procedure was repeated with another six pairs. The motherless group disappeared first in four pairs. Both groups of a fifth pair disappeared between visits and neither group of a sixth pair had disappeared at the end of the sixth day. Generalist predators, chiefly myrmecine ants and polybiine wasps, preyed upon some motherless larval groups within an hour after removing the mother. On one occasion a Polybia sp. wasp discovered a group within 5-10 minutes of removing the mother. The wasp returned at 2-4 minute intervals to remove larvae until the group was completely gone.

\section{Pupation.}

After consuming their last leaf, penultimate instar larvae moved 1-2 m down their host plant to pupate, followed by their mother. The location of a pupal aggregation is often revealed by a stem which has been girdled by larvae as they descended to pupate. At the pupation site, often only $0.5 \mathrm{~m}$ or so above the ground, larvae form a tight cluster of bodies completely encircling the stem (Fig. 1c). The mother normally stands motionless for long periods of time on the backs of her pharate larvae or pupae. Movement in the vicinity of the aggregation often stimulated her to begin walking briskly and repeatedly around and over the group. No interactions were observed between mothers on pupae and predators.

Twenty-seven pupal masses were collected during September and October of 1978 from the "forest" and "field" sites and allowed to develop in the laboratory. Ten to 17 days passed in the lab before adults began to eclose. Teneral adults eclosed from 68 percent of the pupae, parasitoids from 14.3 percent and the remaining 17 percent 


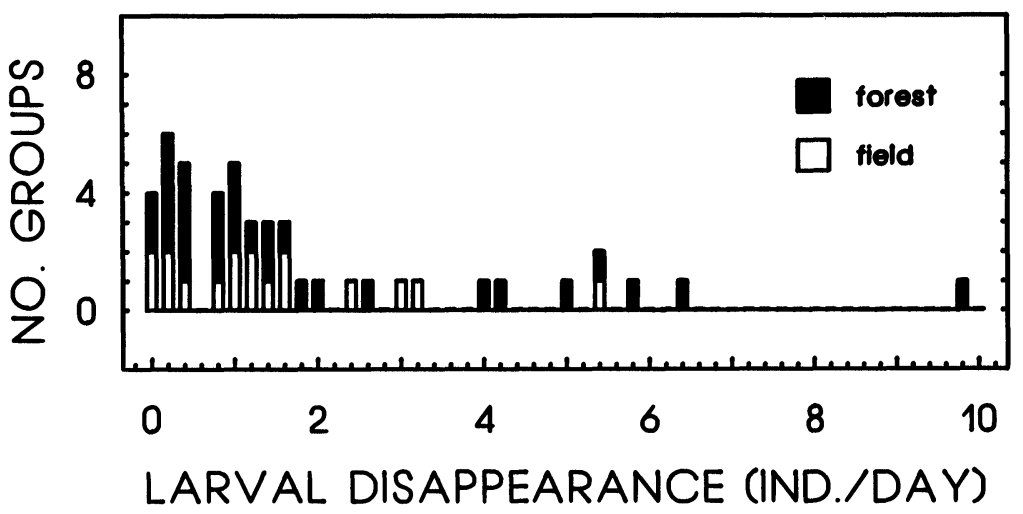

Fig. 3. Comparison of the disappearance rates (number of individuals disappeared per day of observation) for larval groups at the "forest" (solid bar) and "field" sites.

failed to develop (Table 3). Thirteen pupal masses (48\%) produced at least some parasitoids. Numerically, tachinid flies eclosing from nine groups were roughly twice as important as chalcid wasps. The number of parasitoids reared could under estimate their importance since some pupal masses were collected soon after they had formed. However, I suspect that most parasitoids infect larvae and are carried to the pupation site. At least one other larval parasitoid that is worth noting is carried to the pupation site, although it was not reared from the 1978 sample. Several pupal groups collected in the early wet season of 1986 contained larvae of the entomophagous moth, Schacodontia sp. (Pyralidae), an important predator on the gregarious larvae of the cassidine beetle, Polychalma multicava Latreille (pers. obs).

Sixty-five larvae (17\%) in 14 pupal masses of the 1978 sample failed to develop - a loss roughly the same as that to parasitoids. Again, it is unclear why development in these individuals does not proceed. In this case there is the possibility that some individuals do not feed sufficiently as larvae before moving en masse with their siblings to the pupation site. If there is significant variation in feeding within groups, then there could be conflict about the timing of the descent to the pupation site. Of course, larvae may wither at the pupation site because of parasites, fungi, etc. 
Table 3. The number of pupae and pupal groups reared in the lab producing parasitoids, teneral adults and not developing.

\begin{tabular}{lrrrr}
\hline & \multicolumn{2}{c}{ Pupae } & \multicolumn{2}{c}{ Pupal Groups } \\
& N & $\%$ & N & $\%$ \\
\hline Parasitoids & & & & \\
Chalcidae & 18 & 4.8 & 5 & 18.5 \\
$\quad$ Tachinidae & 36 & 9.5 & 9 & 33.3 \\
Adults & 258 & 68.4 & 27 & 100.0 \\
Undev. pupae & 65 & 17.2 & 13 & 48.1 \\
Totals & 377 & 100.0 & 27 & 100.0 \\
\hline
\end{tabular}

\section{Adults}

Females terminated their care when adult beetles began to eclose. Freshly eclosed adults are a pale tan color and a week or more passes before elytra harden. Tenerals remain loosely aggregated for several days feeding heavily on leaves of the natal plant or nearby shoots before dispersing. No mating activity of predispersal adults was observed. The number of days between eclosion and oviposition for both teneral females and guarding mothers remains undetermined. Marked females kept on potted plants lived over most of one wet season and produced a succession of clutches.

\section{Sex Ratio}

The ratio of the sexes at eclosion was examined by recording the number of male and female tenerals emerging from twenty pupal masses collected in May 1986. Males were more numerous in ten, females in seven and the sexes equally represented in three. Males comprised 50.5 percent of all individuals $(n=378)$. Thus, there is no difference in the representation of the sexes above what is expected by chance. If males were competing strongly among themselves for sister matings prior to dispersal and if sex ratio were heritable, then mothers might be expected to lay more female than male eggs (Hamilton 1967).

\section{Sexual dimorphism}

Acromis sparsa is easily distinguished from other Cassidinae in Panama by its sparsely pigmented, translucent and broad elytra which extend roughly half of the body's width to each side of the abdomen (Fig. 4). Additionally, striking differences exist in the shape of some individuals. I examined morphological differences between the sexes by taking six measurements, three from the elytra, 


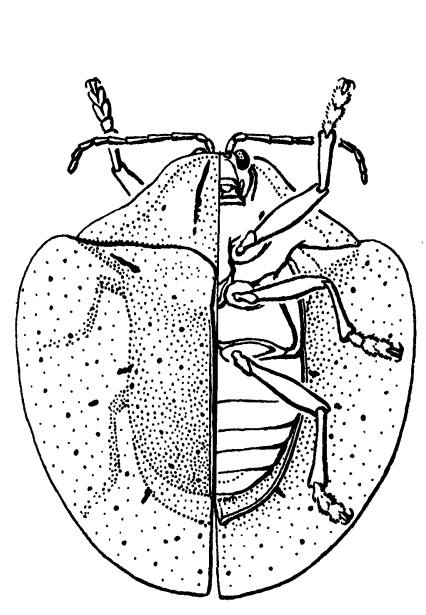

A

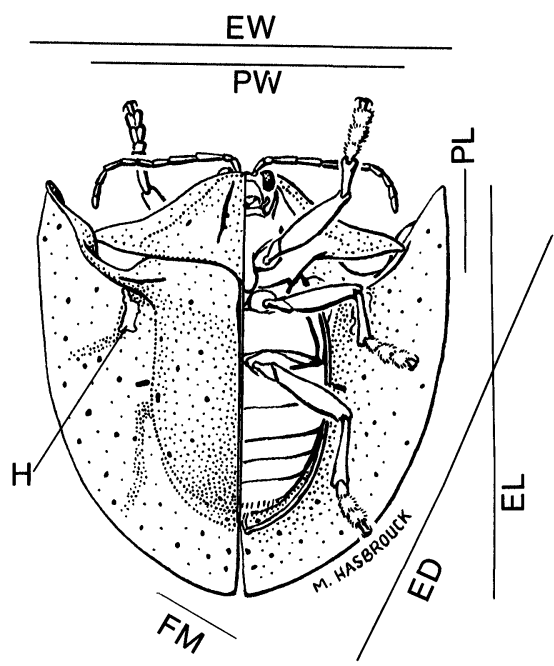

B

Fig. 4. Dorsal (left) and ventral (right) views of (A) a large female and (B), a large male Acromis sparsa. Note the hole " $\mathrm{H}$ " in the elytra of the male. The six measurements taken from pinned specimens were: "PW" = pronotum width, "PL"= pronotum length, " $E L "=$ elytra length, "EW" = elytra width, "ED" = elytra diagonal and "FM" = femora length.

two from the pronotum and one from the hind femora, from 30 pinned females and 71 males spanning much of the size distribution in each sex. Regressions were calculated for all pairwise combinations of these six measurements in each sex -30 regressions in all. The simple linear regression coefficients ranged from 0.922 to 0.983 indicating good fit to linear models throughout. Male and female regression lines were parallel in six of the fifteen possible comparisons and three had equal intercepts (Table 4).

Graphed against femur length, there were no differences between the sexes in the slope of regression lines for pronotum length, elytra width or elytra length. Only elytra width had a significantly different intercept. For any given body size, the elytra of females were slightly wider than those of males. Elytra diagonal length and pronotum width increase much more quickly in males than females relative to femor length (Fig. 5). However, there is little if any sexual difference in these characters in the small end of the size distribution. 
Table 4. The lower left portion of the matrix contains the probabilities that male and female regression lines in each comparison have the same slope. The upper right portion contains probabilities that male and female regression lines have the same intercept. Intercepts have been computed only for those cases where slopes are homogenous. $\mathrm{PW}=$ pronotum width, $\mathrm{PL}=$ pronotum length, $\mathrm{EW}=$ elytra width, $\mathrm{EL}=$ elytra length, $\mathrm{ED}=$ elytra diagonal, $\mathrm{FM}=$ femora length.

\begin{tabular}{lrrrrr}
\hline \multicolumn{5}{c}{ Morphological Character } & \\
& PW & PL & EW & EL & FM \\
\hline PL & $<0.001$ & - & 0.252 & 0.008 & 0.628 \\
EW & $<0.001$ & 0.866 & - & $<0.001$ & 0.027 \\
EL & $<0.001$ & 0.146 & 0.169 & - & 0.061 \\
FM & $<0.001$ & 0.417 & 0.534 & 0.226 & - \\
ED & 0.004 & 0.002 & $<0.001$ & $<0.001$ & $<0.001$ \\
\hline
\end{tabular}

Some aspects of beetle shape changed abruptly with incresing size in some individuals and were impossible to quantify. For instance, the elytra surface near the humeral angle which is an evenly curved surface in small and intermediate males is a complexity twisted surface in large males. Additionally, an oblong perforation as large as $2.5 \times 1.5 \mathrm{~mm}$ was present in approximately the same location in the elytra of many males (Fig. 4). The abdomen lies just central to the holes and apparently is never penetrated. Only males whose elytra length exceeded $8 \mathrm{~mm}$ were perforated (Fig. 6). The elytra of recently eclosed, large males (elytra length $8 \mathrm{~mm}$ ) often lacked any perforation or occasionally had a single narrow slit in one side. Recently opened holes in young individuals sometimes had the appearance of having been punched inward from the dorsal side. The holes of older males were jagged in outline and widened into elipses. The shape of a few holes resembled a cross indicating that a planar object had been inserted and then twisted by 90 degrees. Sectioned elytra from young males showed clearly that the thickness of the elytra varies considerably and is thinnest in the area where holes normally occur.

\section{Interactions at the oviposition site}

Individual males, large enough to be easily distinguished from females, tended to reside on leaves toward the apex of $M$. umbellata shoots where ovipositing and guarding females were also common (Table 1). Activity increased noticeably between 1000 and $1200 \mathrm{hrs}$. 

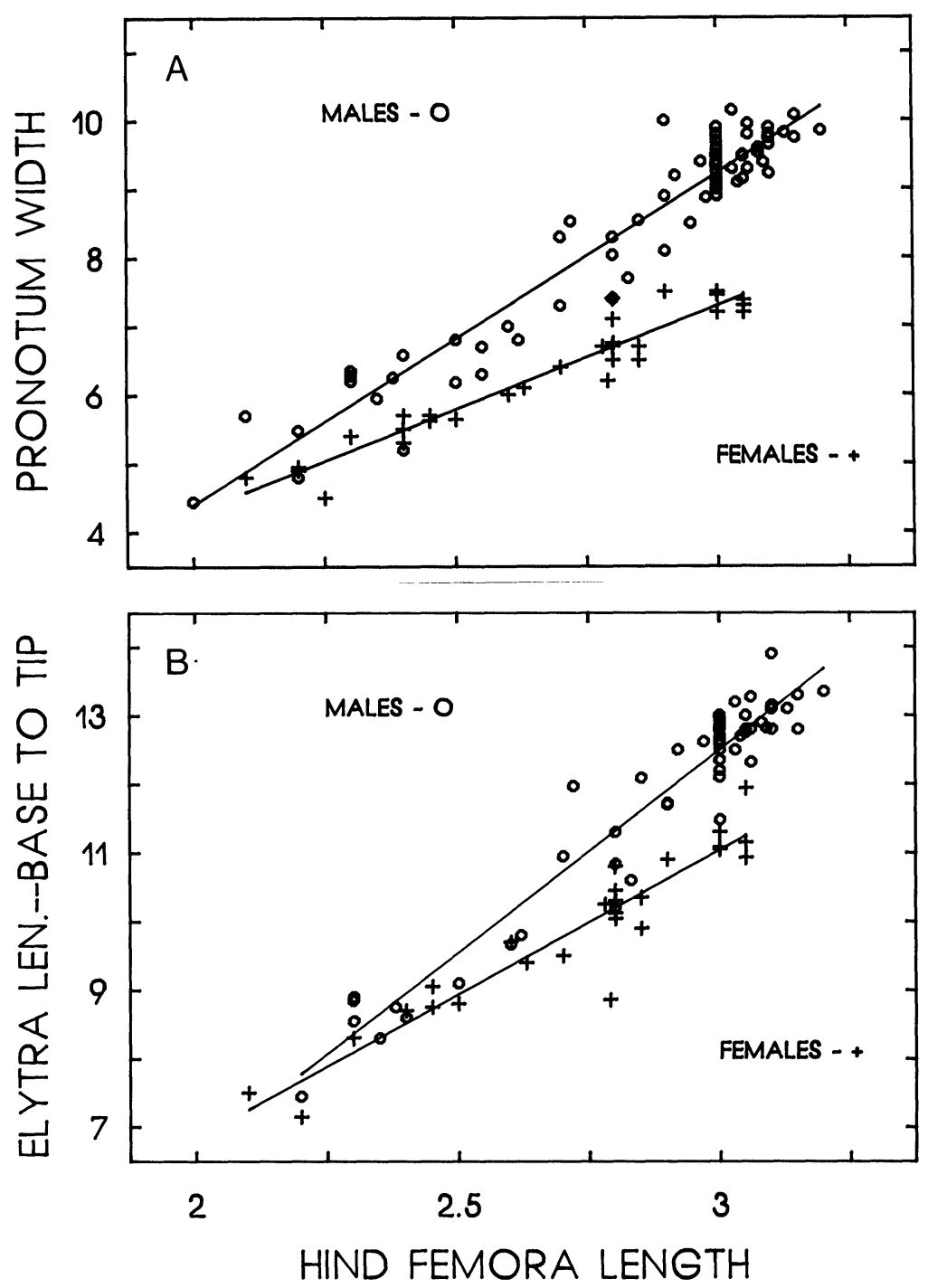

Fig. 5. Sexual differences in the relationship of pronotum width (A) and elytra diagonal length (B) to femur length. 


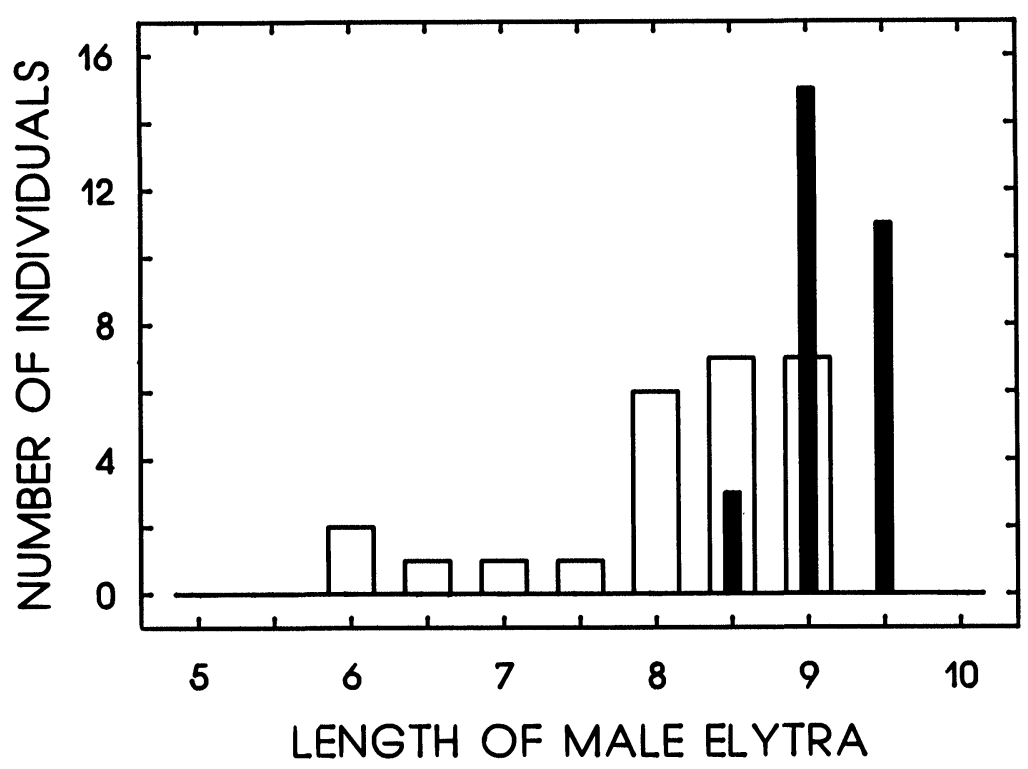

Fig. 6. The size-frequency distribution of males with (solid bars) and without elytral holes in one sample.

of most days as males ascended the vine from roosts under low and intemediate height leaves.

I first became aware of the intensity of competition at these sites when I observed a male-male chase which ended with one male flipping the other from a tip leaf. A few minutes later, I observed two males near the tip of a nearby plant with elytra locked firmly together. After several minutes the two separated and spent some minutes antennating one another. This was followed by maneuvering in which one male attempted to run around the other which pivoted in place. Eventually one male was chased down the petiole where it lost its grip and fell from the plant. The male that remained walked to the female on the first unfolded tip leaf and immediately copulated. Within three to four minutes, the male that had fallen from the plant had climbed back and approached to within two inches of the pair. Antennating began again and the mounted male withdrew his aedeagus but remained on top of the female to confront the intruding male. After two minutes the mated pair separated and the two males again clasped elytra and tugged against the 
other. Eventually, one of the males ran off and the female retreated to a nearby leaf.

Male-male encounters were easily staged by bringing two vine tips with resident males into contact or by transferring a male with a blade of grass. On several occasions the transferred male antennated the resident for 10 to 20 minutes and then walked off the leaf. Other encounters ended with one male rapidly chasing or flipping the other from the leaf. Using staged encounters of this sort it should be possible to directly investigate the importance of size in determining the outcome of male-male competition. Indirect evidence suggests that larger males are often the winners. Of twenty-one unmanipulated plants each with more than one male present, the largest male was nearer the vine tip in sixteen cases (2-sided, binomial probability $=0.03$ ).

Males were occasionally observed locked firmly together for considerable periods of time, always on the host-plant and usually on or just below the youngest leaves of the plant. One male would be normally standing on the substrate supporting a second male held rigidly in the air, feet free, body perpendicular to the substrate (Fig. 7). The lower male was often simultaneously courting or copulating with a female. The lifted male was held by the elytra tip caught between the posterior edge of the pronotum and the leading edge of the elytra of the lower male. The pronotum of the lifted male was inserted into the elytral hole of the lower male. Thus, it appears that elytra holes may be made by opponents as they are flipped up and their pointed elytra pulled down onto the elytra of the lower male. Elytral holes may thus facilitate holding an opponent in a locked position for a period of time during which it is helpless to interfere with mating or attempting to mate with a female.

\section{Discussion}

Female $A$. sparsa guard their offspring on apical foliage against predators and parasitoids from oviposition through pupation. Unlike the larvae of many Cassidinae without parental care, $A$. sparsa larvae are seemingly defenseless without their mother. Predation comes swiftly and inevitably as ants and wasps quickly discover and harvest undefended larvae. Mortality in defended groups takes the form of a slow attrition of offspring over the entire development 


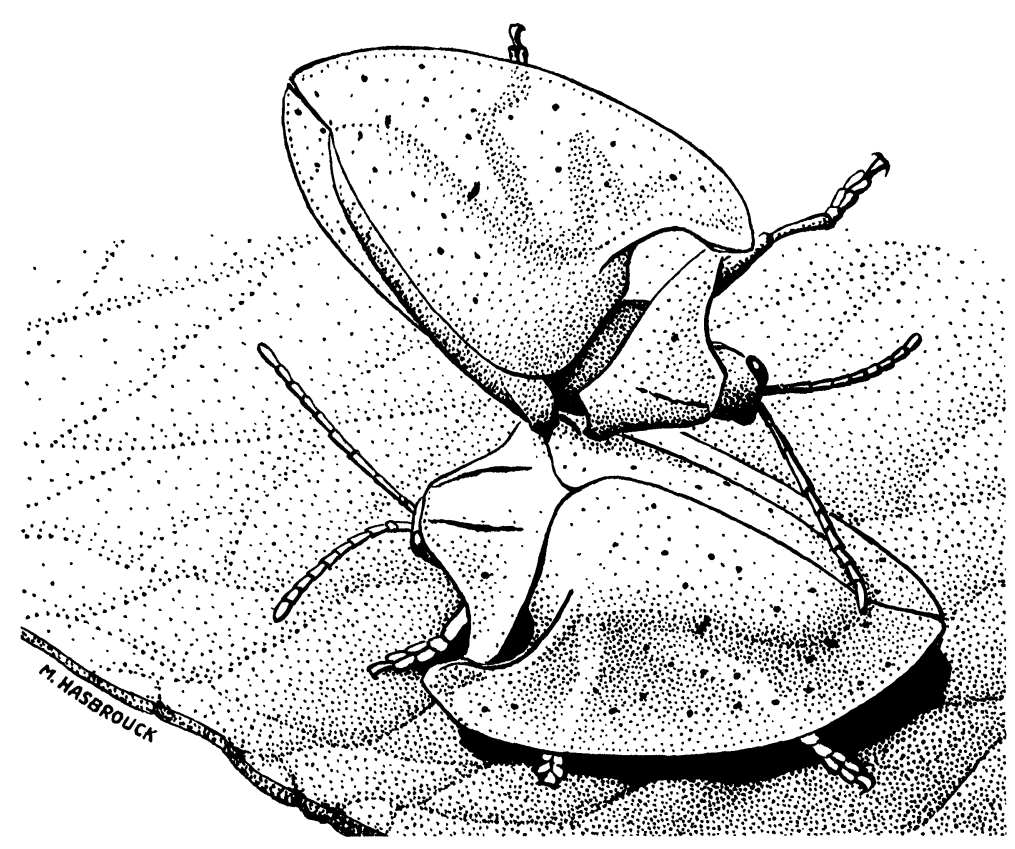

Fig. 7. A competitive encounter in which one male has been lifted from the leaf surface by another male which has gotten a hold on his elytra.

period and is often less than complete. Guarding females are efficient at repelling ants and wasps, but egg parasitoids, larval parasitoids such as chalcid wasps and tachinid flies, pentatomid bugs and an entomophagous moth were able to gain access to guarded offspring. These opportunities arose as groups moved between feeding sites or as individuals temporarily became separated from the rest of the group guarded by the mother.

Maternal care in this species seems to have a clear and unambiguous selective value: as in many other subsocial insects, it lowers mortality due to predation (Tallamy and Wood 1986). Why, then, has subsociality evolved in $A$. sparsa but not in many other cassids some of whom share the same host plant? It may be significant that of the six species of Cassidinae on M. umbellata, only larvae of $A$. sparsa heavily exploit the terminal foliage. The other 5 species can be found anywhere on the plant, but their larvae tend to occur low 
on shade leaves. One hypothesis is that predators are more numerous on apical foliage and maternal care is more effective defense under these circumstances than the defensive attributes of solitary species (eg. egg and larval crypticity, spines, fecal shields, etc.). Apical foliage may harbor higher numbers of predators because it is more open, more easily searched by polybiine wasps and other flying predators, and is nearer the active nectaries of other plants which concentrate such visitors (Hespenheide 1985).

While the possibilities of larval survival may decrease toward the apex of the plant, nutritional rewards could increase. There is a growing body of evidence that insects feeding on young foliage grow more quickly and achieve larger pupal weights and adult size (Schroeder 1986, Damman 1986 and references therein). Larval developmental time should have a direct bearing on the number of groups of offspring a female can guard in a season.

Most Cassidinae are sexually monomorphic or are very nearly so. Eberhard (1980) concluded after reviewing numerous examples that most beetles use their horns to physically displace their conspecific, sexual rivals at the location of important resources. The sexual dimorphism in $A$. sparsa, laterally elongated pronotum and elytra in large males, has probably evolved as a result of similar selection pressures. The chasing, flipping and immobilization of rivals which I observed suggest the existence of strong intrasexual competition although any size related advantages of these morphologies in $A$. sparsa have yet to be demonstrated.

Why does strong competition between males exist in $A$. sparsa and not in many other Cassidinae? Females spend much of their time guarding offspring to the near exclusion of other activities. Although females with brood were occasionally courted by males, most did not attract nearby males. A large proportion of the female population leaves the mating pool during the time offspring are being guarded. Males, on the other hand, do not guard and are presumably sexually competent the entire time. As females begin to look for oviposition sites, which in themselves may be limiting, the operational sex ratio should be heavily biased in favor of males.

While females become a rare item for males during brooding, their eventual reappearance should at least be fairly predictable: they nearly all go to the second or third open leaf on vine tips to oviposit. Larger males capitalize on this predictability by holding these sites and awaiting the arrival of females. Smaller males appear 
to have some opportunities for mating with females still searching for quality oviposition sites. The vigorous competition which I observed between large males was apparently for the last mating before oviposition. This suggests the existence of sperm precedence and an advantage to the last mating male (Smith 1984). Locking an opponent above the back may be one of several ways individuals of this species insure that theirs was the last mating before oviposition.

\section{SUMMARY}

Females of the neotropical tortoise beetle, Acromis sparsa, invested 40 or more days per generation in post ovipositional care of offspring. Broad elytra were used to shield eggs, larvae and pupae from invertebrate enemies. No egg masses or larval groups from which mothers were removed escaped opportunistic predators for longer than a few days. Defended groups suffered a slow attrition of offspring to parasitoids. Thirty-two to 75 percent of eggs, 3 to 11 percent of larvae and 68 percent of pupae survived to the next developmental stage in defended groups. The considerable variation in survival was generated by large differences in the importance of egg parasitoids among sites.

Courtship, mating, oviposition and early larval feeding occurred on apical foliage of the second-growth vine, Merremia umbellata (Convolvulaceae). Males attempted to chase, immobilize or dislodge competing males at these sites-often before females had arrived to oviposit. Of several characters measured, only those involved in combat, pronotum width and the extension of the humeral angle of the elytra, increased more rapidly in males than females with increasing body size. The elytra of most large males had small oblong holes, opened while young and subsequently enlarged by the entry by the pronota of opponents during combat. Holes appeared to help lock an opponent above the back where it was helpless to interfere or supercede in mating.

\section{ACKNOWLEDGMENTS}

I thank the Smithsonian Tropical Research Institute for providing financial and logistical support. The paper benefited from the critical reviews of A. Aiello, W. Eberhard, W. Nentwig, N. Smith and H. Wolda. H. Stockwell and D. Englemann provided identifications of the important species and encouragement throughout. E. 
Munroe kindly identified Schacodontia. I am also indebted to M. Hasbrouck for the drawings and to $\mathrm{C}$. Windsor for the maternal care of our offspring while I was in the field.

\section{REFERENCES}

ARNETT, R. H.

1968. The Beetles of the United States (A manual for Identification). The American Entomological Institute, Ann Arbor, Michigan, U.S.A.

Austin, D. F.

1975. Family 164. Convolvulaceae. Flora of Panama, Part IX. Ann. Missouri bot. Gard., 62: 157-224.

BLACK WELDER, R. E.

1982. Checklist of the coleopterous insects of Mexico, Central America, the West Indies, and South America. U.S. Nat. Mus. Bull. 185, parts 1-6, reprint.

Carroll, C. R.

1978. Beetles, parasitoids and tropical morning glories: a study in host discrimination. Ecol. Entom. 3: 79-85.

Damman, $\mathrm{H}$.

1987. Leaf quality and enemy avoidance by the larvae of a pyralid moth. Ecology 68: 88-97.

EBERHARD, W. E.

1975. The ecology and behavior of a subsocial pentatomid bug and two scelionid wasps: strategy and counterstrategy in a host and its parasites. Smiths. Contr. Zool., No. 205: 1-39.

1980. Horned beetles. Sci. Am. 242: 166-182.

EICKWORT, G.

1981. Presocial insects. Social Insects, 2: 199-280, Acad. Press.

Eisner, T., E. van Tassell, and J. E. Carrell

1967. Defensive use of a "fecal shield" by a beetle larva. Science 158: 1471-73. FiebRIG, $\mathrm{K}$.

1910. Cassiden und Cryptocephaliden Paraguays. Zool. Jahrb., Supplement XII: 11-264.

Hamilton, W. D.

1967. Extraordinary sex ratios. Science 156: 477-88.

HeSPENHEIDE, H. A.

1985. Insect visitors to extrafloral nectaries of Byttneria aculeata (Sterculiaceae): relative importance and roles. Ecol. Entom. 10: 191-204.

HINCKs, W. D.

1952. The genera of the cassidinae (Coleoptera: Chrysomelidae). Trans. Roy. Ent. Soc. Lond. 103: 327-362.

Hinton, H. E.

1944. Some general remarks on sub-social beetles, with notes on the biology of the staphylinid, Platystethus arenarius (Fourcroy). Proc. R. Ent. Soc. Lond. (A) 19: 115-128.

LINSENMAIER, $\mathrm{W}$.

1972. Insects of the World. McGraw-Hill, New York, 392 pp. 
MiCHENER, C. D.

1969. Comparative social behavior of bees. Ann. Rev. Entom. 14: 299-342.

Ohaus, F.

1899-1900. Bericht über eine entomologische Reise nache Zentralbrasilien. Stettin. ent. Ztg. 60: 204-45 (1899); 61: 164-91 (1900).

1909. Berichte über eine entomologische Studienreise in Südamerika. Stettin. ent. Ztg. 70: 3-139.

ODHIAmbo, T. R.

1959. An account of parental care in Rhinocoris albopilosus Signoret (Hemiptera-Heteroptera: Reduviidae), with notes on its life history. Proc. Royal Ent. Soc., London. (a) 34: 175-185.

O'Toole, C. AND K. Preston-Mafham

1985. Insects in Camera. Oxford University Press; Oxford.

SCHROEDER, L. A.

1986. Changes in tree leaf quality and growth performance of lepidopteran larvae. Ecology 67: 1628-36.

SHELFORD, R. W.

1916. A Naturalist in Borneo. T. Fisher Unwin Ltd., London.

SMITH, R. L.

1984. Sperm Competition and the Evolution of Animal Mating Systems. Academic Press; Orlando, Fla., 687 pp.

Tallamy, D. W. AND R. F. Denno

1981. Maternal care in Gargaphia solani (Hemiptera: Tingidae). Anim. Behav. 29: 771-778.

Tallamy, D. W. and T. K. Wood

1986. Convergence patterns in subsocial insects. Ann. Rev. Entom. 31: 369-90. VON LENGERKEN, $\mathrm{H}$.

1954. Die Brutfürsorge und Brutpflegeinstinkte der Käfer. Akademische Verlagsgesellschaft, Geest \& Portig, Leipzig 1954.

WILSON, E. O.

1971. The Insect Societies, Belknap Press, 548 pp. 

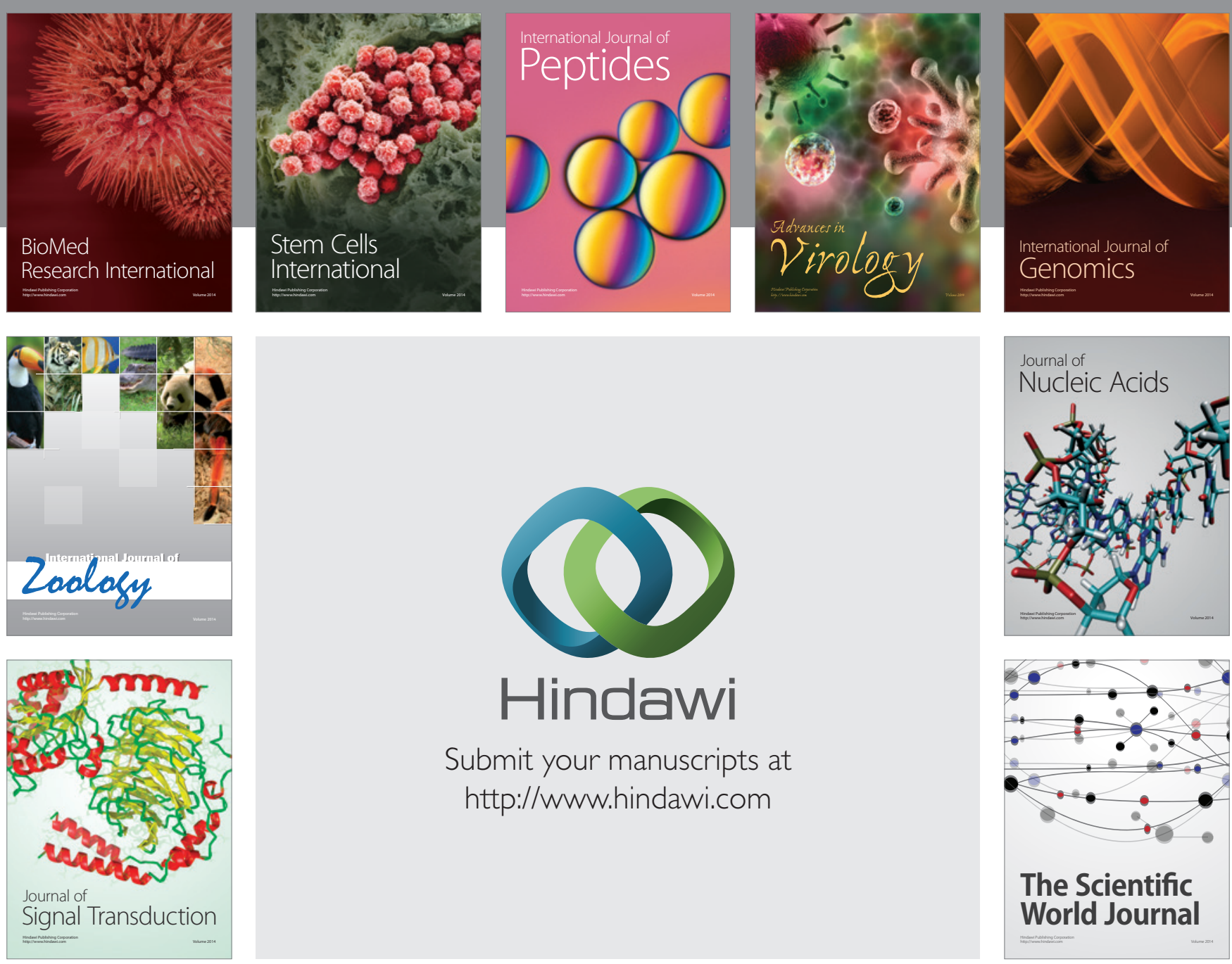

Submit your manuscripts at

http://www.hindawi.com
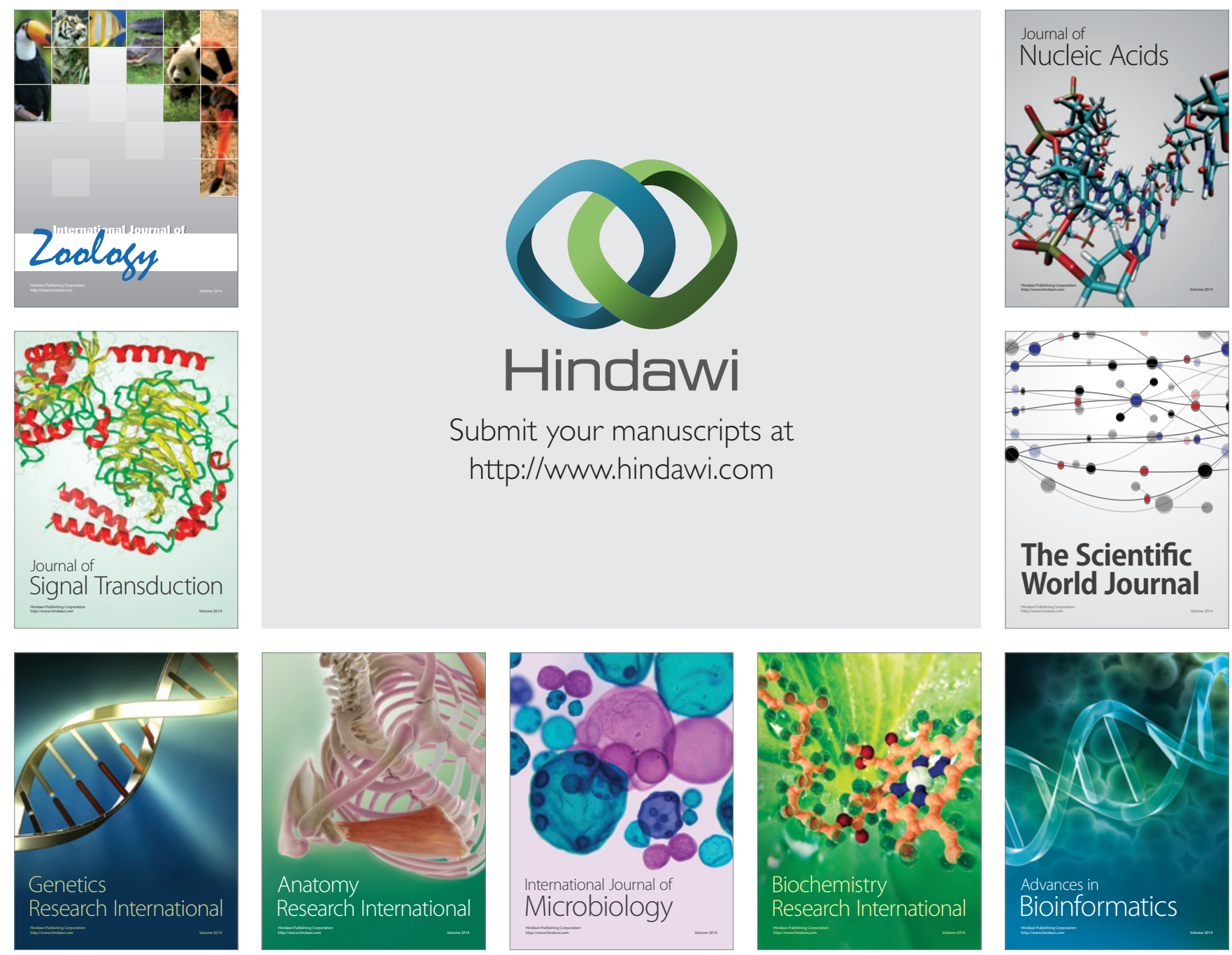

The Scientific World Journal
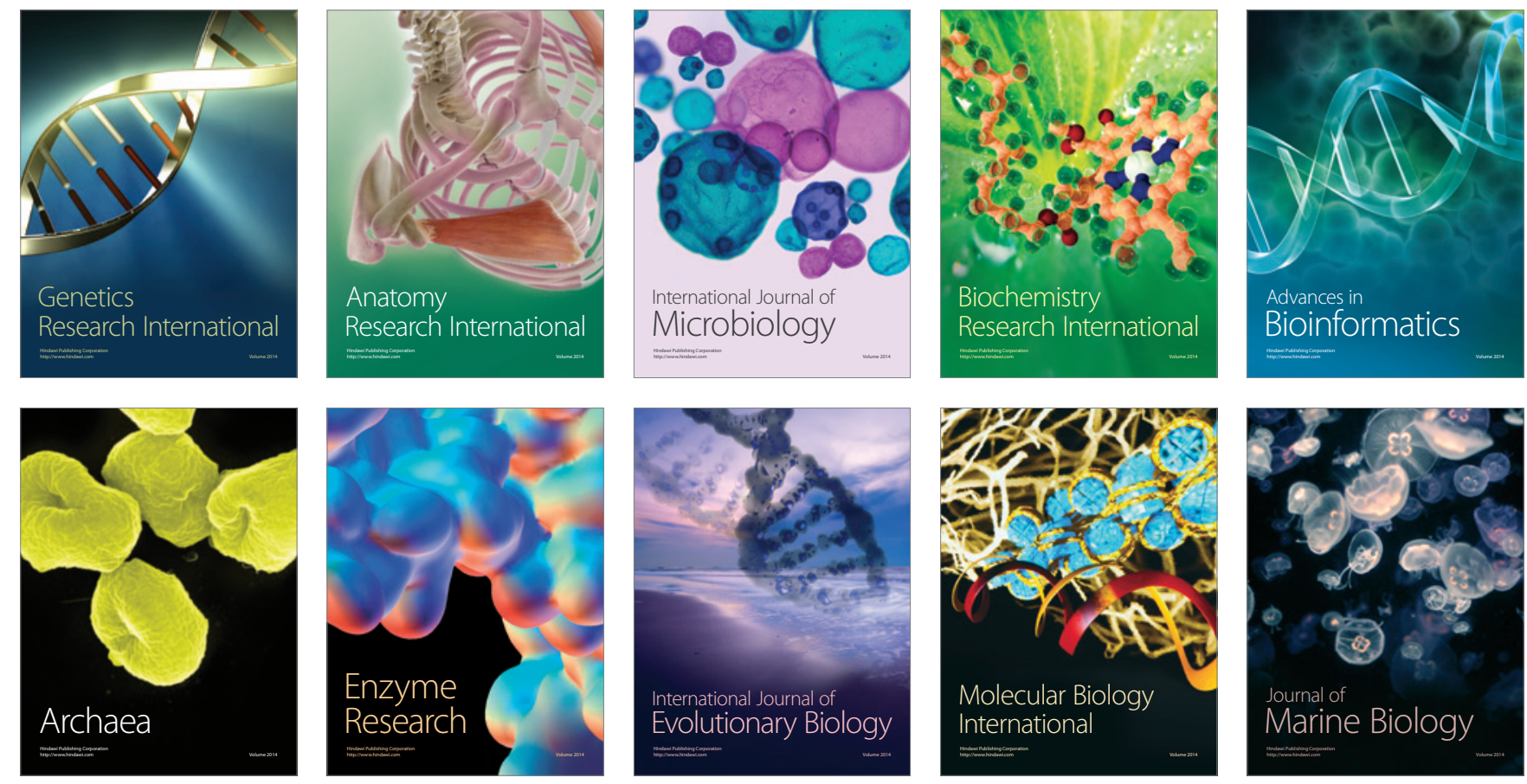